\title{
Inclusion complexes and self-assembled cyclodextrin aggregates for increasing the solubility of benzimidazoles
}

\author{
Leticia Norma Carpentieri Rodrigues ${ }^{\circledR} 1^{*}$, Anna Carollina Moraes Tavares ${ }^{1}$, Beatriz Tavares \\ Ferreira $^{1}$, Adriana Karla Cardoso Amorim Reis ${ }^{1}$, Luciana Morita Katiki²
}

\begin{abstract}
${ }^{1}$ Instituto de Ciências Ambientais, Químicas e Farmacêuticas, Universidade Federal de São Paulo, Diadema, São Paulo, Brazil, ${ }^{2}$ Secretaria de Agricultura e Abastecimento do Estado de São Paulo, Instituto de Zootecnia - IZ, Agência Paulista de Tecnologia dos Agronegócios - APTA, Nova Odessa, São Paulo, Brasil.
\end{abstract}

\begin{abstract}
Albendazole and fenbendazole are imidazole derivatives that exhibit broad spectrum activity against parasites, but the low solubility of these drugs considerably reduces their effectiveness. Complexation of albendazole and fenbendazole with cyclodextrins ( $\beta$-cyclodextrin and hydroxypropyl- $\beta$-cyclodextrin) in both water and an aqueous solution of polyvinylpyrrolidone (PVP-k30) was studied to determine if it could increase the solubility and dissolution rate of the drugs. In an aqueous solution, $\beta$-cyclodextrin increased the solubility of albendazole from 0.4188 to $\sim 93.47 \mu \mathrm{g} \mathrm{mL}^{-1}(223 \times)$, and of fenbendazole from 0.1054 to $45.56 \mu \mathrm{g} \mathrm{mL}^{-1}(432 \times)$; hydroxypropyl- $\beta$-cyclodextrin, on the other hand, increased solubility to $\sim 443.06$ $\mu \mathrm{g} \mathrm{mL}^{-1}(1058 \times)$ for albendazole and $\sim 159.36 \mu \mathrm{g} \mathrm{mL}^{-1}(1512 \times)$ for fenbendazole. The combination of hydroxypropyl- $\beta$-cyclodextrin and polyvinylpyrrolidone enabled a solubility increase of $1412 \times(\sim 591.22$ $\left.\mu \mathrm{g} \mathrm{mL} \mathrm{mL}^{-1}\right)$ for albendazole and $1373 \times\left(\sim 144.66 \mu \mathrm{g} \mathrm{mL}^{-1}\right)$ for fenbendazole. The dissolution rate of the drugs was significantly increased in binary and ternary systems, with hydroxypropyl- $\beta$-cyclodextrin proving to be more effective. The presence of the water-soluble PVP-k30 increased the dissolution rate and amorphization of the complexes. Analysis of the changes in displacement and the profile of the cyclodextrin bands in the ${ }^{1} \mathrm{H}$ NMR spectra revealed a molecular interaction and pointed to an effective complexation in the drug/cyclodextrin systems. Monomeric forms and nanoclusters of cyclodextrins were observed in the drug/cyclodextrin systems, suggesting that the increase in solubility of the drugs in the presence of cyclodextrins should not be attributed only to the formation of inclusion complexes, but also to the formation of cyclodextrin aggregates.
\end{abstract}

Keywords: Cyclodextrins/pharmacokinetics. Benzimidazoles/administration \& dosage. Inclusion complexes. Cyclodextrin aggregates. Drug liberation/drug effects. Antiparasitic agents/analysis. Albendazole/analysis. Fenbendazole/analysis.

\section{INTRODUCTION}

Benzimidazoles (BNZs) are a class of chemotherapeutic agents with broad biological activity. They are employed as antiparasitic agents and antibacterial agents, and recently, important antitumor activity has been described (Duan, Liu, Rockwell, 2013). In addition, nitroaromatic derivates of benzimidazole are being studied for the treatment of tuberculosis and malaria (Camacho et al., 2011). Despite its wide-ranging biological activities,

\footnotetext{
*Correspondence: L. N. C. Rodrigues. Instituto de Ciências Ambientais, Químicas e Farmacêuticas, Universidade Federal de São Paulo. Rua São Nicolau, 210, 09913-030, Diadema, São Paulo, Brazil. Telephone/Extension line: +55 11 4044-0500/3576. E-mail: leticia.carpentieri@gmail.com
}

the low solubility of this class of substances has resulted in its inefficiency as a therapeutic agent, and parasitic and bacterial resistance against it has emerged.

Different strategies have been investigated to solve the limited aqueous solubility of benzimidazoles, including the use of surfactants, such as polysorbates and bile salts, or co-solvents (Daniel-Mwambete et al., 2004; Miranda et al., 2011; Pradines et al., 2014). There is evidence that complexation with cyclodextrins (CDs) can increase the oral bioavailability of benzimidazoles (Evrard et al., 2002; Moriwaki et al., 2008; Pourgholami, Wangoo, Morris, 2008; Palomares-Alonso et al., 2010; Kumar et al., 2011a; Kumar et al., 2011b; Alamdarnejad et al., 2013; De Jaeghere et al., 2013; Pradines et al., 2014; Ferreira et al., 2015). CDs are known for increasing 
the solubility, dissolution efficiency, and bioavailability of different drugs through the formation of inclusion complexes. Recently, it has been observed that CDs are capable not only of forming inclusion complexes, but also of self-organizing to form nanoclusters that can contribute to the dissolution of low solubility drugs (Heydari, Kakhki, 2013; Kurkov, Loftsson, 2013).

Stella and Rajewski (1997) have pointed out that the mechanism involved in the increase of BNZ solubility by the addition of CDs has advantages compared to that by the addition of co-solvents and surfactants. In the case of co-solvents and surfactants, the increase in solubility occurs through changes in the properties of the solution, and any change in the medium can compromise the solubilization of the drug. On the other hand, dissolution through the formation of inclusion complexes with CDs is not influenced by the medium.

The objective of this study was to develop and characterize the inclusion complexes of benzimidazole2-carbamates (albendazole and fenbendazole) and cyclodextrins, and to evaluate the effect of the cyclodextrins on the solubility of these drugs.

\section{MATERIALS AND METHODS}

\section{Chemicals and reagents}

Albendazole (ABZ), fenbendazole (FBZ), polyvinylpyrrolidone (PVP-k-30, molecular weight $360,000)$ and hydroxypropyl- $\beta$-cyclodextrin (HP $\beta C D)$ were obtained from Sigma-Aldrich Co. (São Paulo, Brazil). $\beta$-Cyclodextrin ( $\beta C D$, molecular weight 1135 ) was kindly provided by Labonathus Health Solutions (São Paulo, Brazil). Acetonitrile (HPLC grade) was obtained from J. T. Baker. Ultra-purified water was obtained through the Thermo Scientific reverse osmosis system. All other reagents were of analytical grade.

\section{HPLC determination}

The criteria used were based on the methodology described by Rodrigues, Reis, and Katiki (2016).

The BNZs (ABZ or FBZ) were quantified using an HPLC (Shimadzu Prominence Modular HPLC) with a diode-array detector set at a wavelength of $300 \mathrm{~nm}$, a mobile phase of acetonitrile:0.04 $\mathrm{M}$ diammonium hydrogen phosphate $(41: 59 \mathrm{v} / \mathrm{v})$ with $\mathrm{pH}$ 7.5-7.6, a flow rate of $1.5 \mathrm{~mL} \mathrm{~min}^{-1}$, an injection volume of $20 \mu \mathrm{L}$, and a reverse phase chromatographic column (Kromazil reverse $\mathrm{RP}$ C18, $100 \mathrm{~A}, 5 \mu \mathrm{m}, 250 \times 4.6 \mathrm{~mm}$ ) equilibrated to ambient temperature and eluted under isocratic conditions.
The mobile phase was previously degassed through vacuum filtration (KNF vacuum pump N810.FT.18, 100 mbar) through a $45 \mu \mathrm{m}$ Nylon membrane, followed by sonication in an ultrasonic bath (Altsonic 9L) for $15 \mathrm{~min}$.

Calibration curves were obtained using stock solutions of the drugs (ABZ or FBZ, $100 \mu \mathrm{g} \mathrm{mL}^{-1}$ ). Linear relationships were obtained in the range of 2 to $100 \mu \mathrm{g}$ $\mathrm{mL}^{-1}$ for both drugs; the limit of detection (LOD) and limit of quantification (LOQ) values obtained for ABZ were 0.4855 and $1.6183 \mu \mathrm{g} \mathrm{mL}^{-1}$, respectively; and for FBZ they were 2.4575 and $8.1918 \mu \mathrm{g} \mathrm{mL}^{-1}$, respectively. The analytical performance parameters followed the recommendations of the guide for the validation of analytical methods (ICH, 2005).

\section{Solubility studies}

The phase solubility trials were performed according to the recommendations of Higuchi and Connors (1965). An excess of the drug (ABZ or FBZ) was added to dispersions containing increasing amounts of CDs $(0$ to $\left.40 \mathrm{mmol} \mathrm{L}^{-1}\right)$ in the absence or presence of $0.1 \%$ PVP-k-30 as a co-complexing agent. The dispersions obtained were stirred (DragonLab MS-MS10 10-position magnetic stirrer) and kept at equilibrium for $72 \mathrm{~h}$ at room temperature. After the equilibrium time had passed, aliquots of the supernatant were filtered through a $0.45 \mu \mathrm{m}$ cellulose acetate membrane filter, diluted with the mobile phase, transferred to a $1.5 \mathrm{~mL}$ amber vial, and the amount of drug dissolved was evaluated by liquid chromatography.

The intrinsic solubility of the drugs (ABZ and FBZ) and the solubility of the binary and ternary complexes in purified water were determined using similar conditions.

\section{Preparation of binary and ternary cyclodextrin complexes}

The preparation of the binary (Drug/ $\beta C D$ or Drug/ HP $\beta C D$ ) and ternary (Drug/ $/$ CD-PVP $0.1 \%$ or Drug/ HP $\beta C D-P V P$ 0.1\%) complexes was performed by lyophilization: equimolar quantities of each drug, $\mathrm{ABZ}$ or $\mathrm{FBZ}$, and $\mathrm{CD}, \beta \mathrm{CD}$, or $\mathrm{HP} \beta \mathrm{CD}$, were weighed and dispersed, separately, in purified water. The obtained dispersions were submitted to homogenization (DragonLab MS-MS10 magnetic stirrer) for $2 \mathrm{~h}$, transferred to borosilicate lyophilization vials with a round bottom $(\phi$, $70 \mathrm{~mm} / 300 \mathrm{~mL}$ ), frozen at $-78.5^{\circ} \mathrm{C}$ with dry ice, protected from light by aluminum foil, and lyophilized (Liotop Lyophilizer L101) for $120 \mathrm{~h}$. After freeze-drying, the complexes were crushed in a glass mortar and pulverized in a stainless-steel particle sieve with openings of 0.71 
$\mathrm{mm}$. For the ternary complex, equimolar quantities of drugs and CDs were separately dispersed in a $0.1 \%$ PVP solution $(\mathrm{w} / \mathrm{v})$. The dispersion results were subjected to the previously described conditions for solubility trials.

\section{Thermogravimetric Analysis (TG) and Differential Scanning Calorimetry (DSC)}

DSC curves were obtained by a Shimadzu Differential Scanning Calorimetry DSC-60 system using a sample mass of 2.0 to $4.0 \mathrm{mg}$ in a previously calibrated aluminum capsule with metallic indium $(99.99 \%$ purity; $\left.\mathrm{T}_{\text {fusion }}=156.4{ }^{\circ} \mathrm{C} ; \Delta \mathrm{H}_{\text {fusion }}=28.7 \mathrm{~J} \mathrm{~g}^{-1}\right)$, under a dynamic nitrogen atmosphere $\left(100 \mathrm{~mL} \mathrm{~min}^{-1}\right)$ with a heating rate of $10{ }^{\circ} \mathrm{C} \mathrm{min}^{-1}$ from 40 to $400{ }^{\circ} \mathrm{C}$.

Thermogravimetric curves (TG/DTG) were obtained by a Shimadzu differential thermogravimetry DTG-60 system using a sample mass of 4.0-6.0 $\mathrm{mg}$ in a previously calibrated aluminum capsule with calcium oxalate monohydrate (ASTM 1582-93) under a dynamic nitrogen atmosphere $\left(100 \mathrm{~mL} \mathrm{~min}^{-1}\right)$ with a heating rate of $10{ }^{\circ} \mathrm{C} \mathrm{min}-1$ from 40 to $900{ }^{\circ} \mathrm{C}$. The obtained curves were adjusted with the TA-60WS software.

\section{Powder X-ray Diffraction (P-XRD)}

The powder x-ray diffractograms were obtained with a Bruker diffractometer D8 Advance, using a $\mathrm{Cu} \mathrm{K} \alpha$ radiation source at $40 \mathrm{KV}$ and $40 \mathrm{~mA}$, in the range of 5-60 $(2 \theta)$, with a scan rate of $2^{\circ} \mathrm{min}^{-1}$, using polycrystalline silicon $(\mathrm{Si})$ as the default.

\section{Particle size and zeta potential measurements}

The zeta potential and particle size/distribution measurements were performed on a Zetasizer Nano ZS/Malvern Instruments device. The scattering angle employed was $173^{\circ}$. The samples were diluted in milli-Q water at $25^{\circ} \mathrm{C}$ in a $1: 100(\mathrm{w} / \mathrm{v})$ ratio, submitted to an ultrasonic bath (Altsonic 9L) for $15 \mathrm{~min}$, filtered through a $45 \mu \mathrm{m}$ syringe filter, and taken for analysis. The results are reported as the mean of three measurements.

\section{NMR spectroscopy}

The ${ }^{1} \mathrm{H}$ NMR spectra were obtained at $300 \mathrm{MHz}$ (Bruker Avance, TXI SB $5 \mathrm{~mm}$ ). The compounds were diluted to $\sim 10 \mathrm{mg} \mathrm{mL}^{-1}$ in DMSO- $d_{6}$. The chemical shifts were recorded in $\mathrm{ppm}(\delta)$ using tetramethylsilane (TMS) as an internal reference.

\section{In vitro release studies}

Dissolution trials were performed on an Ethik Technology 299-6/TS dissolution device, using a rotating disc apparatus (Pharmacopeia, 2016), $900 \mathrm{~mL}$ of ultrapure water as a dissolution medium, a stirring speed of $100 \mathrm{rpm}$, and a temperature of $37 \pm 0.5^{\circ} \mathrm{C}$.

For the preparation of the pills, amounts equivalent to $100 \mathrm{mg}$ of the drug (ABZ or FBZ) and of the binary and ternary complexes were weighed and transferred to the matrices (rotating discs), and with the help of a 10ton hydraulic press (Flowscience Instruments \& Trade, Brazil), they were compacted under a pressure of 250 psi for $30 \mathrm{~s}$. Subsequently, the matrices were coupled to the rotating disc apparatus and placed in the dissolution device. Aliquots of $10 \mathrm{~mL}$ were collected at time intervals of $5,10,15,20,30,40,50,60,90,120,180$, and $240 \mathrm{~min}$, and then placed back in the dissolution medium at the same temperature. The amount of dissolved drug was evaluated through liquid chromatography. The values obtained were corrected (Aronson, 1993). The accumulated amount of drug dissolved was plotted as a function of time.

\section{RESULTS AND DISCUSSION}

The main goal of adding CDs to pharmaceutical products is to increase the solubility of low-solubility drugs. The amount of CD needed to obtain the desired solubility is determined by the phase solubility diagram.

The phase solubility diagrams of the drugs $\mathrm{ABZ}$ and FBZ in the presence of $\beta C D$ and HP $\beta C D$ were of the type $A_{L}$ (Figure 1). The linear regression of the data generated angular coefficient values $(S)$ of less than 1 , assuming a stoichiometry of 1:1 (Table I) (Messner et al., 2010). The intrinsic solubility values $\left(S_{0}\right)$ obtained were lower than those observed for the intercept solubility $\left(S_{\text {int }}\right)$, the latter being used to calculate the stability constant of the complexes $\left(k_{1: 1}\right)$ (based on the equation of Higuchi and Connors, 1965):

$$
k_{1: 1}=\text { Slope } / S_{\text {int }}(1-\text { Slope })
$$

where, $k_{1: 1}$ is the stability constant for 1 st order diagrams, Sis the angular coefficient, and $S_{i n t}$ the linear coefficient.

According to Pitha, Szente, and Greenberg (1983), only complexes with a stability constant $k_{c}$ between 200 and $5000 \mathrm{M}^{-1}$ seem to have practical applications, given that the unstable complexes $\left(k_{c}<200 \mathrm{M}^{-1}\right)$ lead to premature release of the drug and the very stable complexes $\left(k_{c}>5000 \mathrm{M}^{-1}\right)$ result in delayed or incomplete release of the drug in the body. For many complexes, 


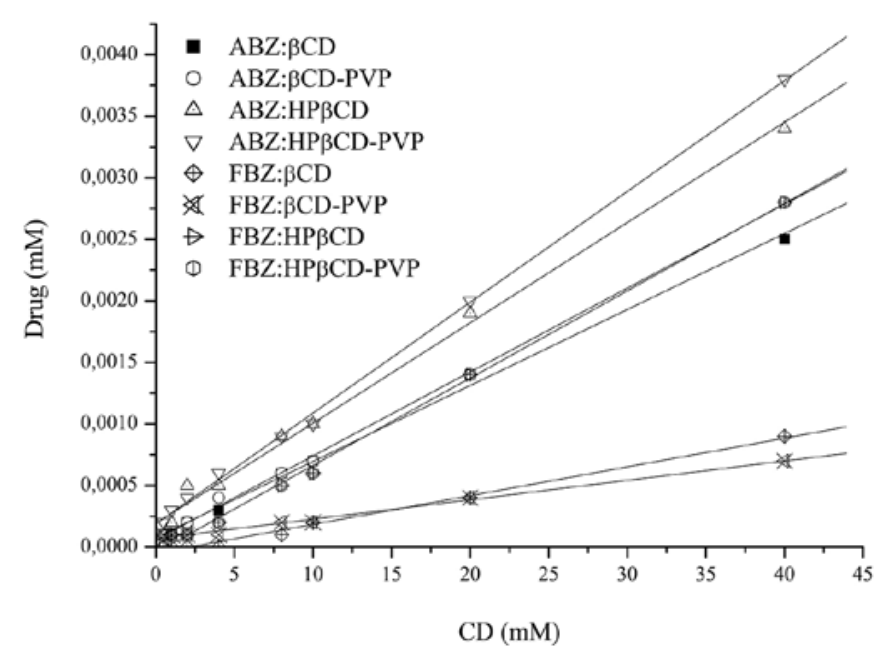

FIGURE 1 - Phase solubility diagram of the drugs (ABZ and FBZ) in the presence of the CDs.

values of $k_{c}$ between 100 to $20,000 \mathrm{M}^{-1}$ can be found (Challa et al., 2005).

The addition of water-soluble polymers to an aqueous solution of CD and drug is often linked to an increase in the stability constant of the complex $\left(k_{c}\right)$ and a reduction of the amount of $\mathrm{CD}$ required for incorporation of the drug (Loftsson, Másson, and Sigurjónsdóttir, 1999). The presence of polymers in drug/CD systems decreases the crystallinity of the drugs and has a synergistic effect on the solubilizing action of the CDs (Kurkov, Loftsson, 2013).

The ternary complexes with ABZ had $k_{1: 1}$ values larger than those of the binary complexes, but this effect was not observed for the FBZ ternary complexes. Since the $k_{1: 1}$ values are strongly affected by the solubility values $\left(S_{\text {int }}\right)$, distortions may be observed due to errors arising from the analytical method.
The solubility of the complexes increased compared to the pure drug (Table II). As expected, the modified cyclodextrin, hydroxypropyl- $\beta$-cyclodextrin, proved to be more effective in dissolving the drugs than the natural cyclodextrin, $\beta$-cyclodextrin.

The formation of inclusion complexes in solution does not necessarily guarantee attainment and isolation of the complexes in the solid state, since these are the result of a set of chemical equilibriums. The solid product may be a fine dispersion of the drug inside the $C D$ or even a mixture consisting of inclusion complexes, noncomplexed drugs, self-organized CD aggregates, and even CDs in the hydrated form.

Many techniques have been used to investigate the formation of inclusion complexes in the solid state, each having its own characteristics that not only allow detection of the formation of inclusion complexes, but also understanding of their chemical structure and the interactions that are established between the various components that make up the system.

Thermo-analytic techniques such as DSC and TG/DTG are widely used for the characterization of supramolecular complexes, such as inclusion complexes with CDs (Table III). The DSC curves of the physical mixtures for both drugs (ABZ or FBZ) had a thermal behavior that is representative of the sum of the substances. In the binary complexes, the event relating to the fusion of the drugs ( $\mathrm{ABZ}$ and FBZ) was maintained, suggesting the presence of free drugs in the medium; the presence of the co-complexing agent PVP proved to be favorable to the amorphization of the drug/CD systems (Table III).

The success of the interaction between the guest molecule and the CD can be qualitatively assessed by comparing the properties of the complexes and the CDs,

TABLE I - Parameters obtained from the linear regression of the curves of the phase solubility diagram

\begin{tabular}{|c|c|c|c|c|c|}
\hline & $S_{0}$ & $S_{i n t}$ & $S$ & $\boldsymbol{R}$ & $k_{1: 1} M^{-1}$ \\
\hline $\mathrm{ABZ}$ & $1.5153 \mathrm{E}-6$ & & & & \\
\hline $\mathrm{ABZ} / \beta \mathrm{CD}$ & & $7.7710 \mathrm{E}-5$ & $6.1735 \mathrm{E}-5$ & 0.9987 & 794 \\
\hline ABZ//CD-PVP $0.1 \%$ & & $5.9415 \mathrm{E}-5$ & $6.8125 \mathrm{E}-5$ & 0.9993 & 1146 \\
\hline $\mathrm{ABZ} / \mathrm{HP} \beta \mathrm{CD}$ & & $1.9162 \mathrm{E}-4$ & $8.1486 \mathrm{E}-5$ & 0.9967 & 425 \\
\hline ABZ/HP $\beta C D-P V P ~ 0.1 \%$ & & $1.8777 \mathrm{E}-4$ & $9.0034 \mathrm{E}-5$ & 0.9994 & 480 \\
\hline FBZ & $3.5202 \mathrm{E}-7$ & & & & \\
\hline $\mathrm{FBZ} / \beta \mathrm{CD}$ & & $4.9647 \mathrm{E}-5$ & $2.3359 \mathrm{E}-5$ & 0.9955 & 471 \\
\hline FBZ/ßCD-PVP 0.1\% & & $6.9020 \mathrm{E}-5$ & $1.5764 \mathrm{E}-5$ & 0.9956 & 228 \\
\hline FBZ/HP $\beta C D$ & & $4.5531 \mathrm{E}-5$ & $7.0927 \mathrm{E}-5$ & 0.9990 & 1558 \\
\hline FBZ/HPßCD-PVP 0.1\% & & $3.9934 \mathrm{E}-5$ & $5.3624 \mathrm{E}-5$ & 0.9983 & 1343 \\
\hline
\end{tabular}

${ }^{*} S_{0}$, intrinsic solubility; $S_{\text {int }}$, linear coefficient; $S$, slope; $R$, correlation coefficient and $k_{1: 1}$, stability constant 
Inclusion complexes and self-assembled cyclodextrin aggregates for increasing the solubility of benzimidazoles

TABLE II - Solubility values obtained for binary and ternary complexes

\begin{tabular}{|c|c|c|c|c|c|c|}
\hline \multirow{2}{*}{ Complexes } & \multicolumn{4}{|c|}{ Solubility $\left(\mu \mathrm{g} \mathbf{m L}^{-1}\right)$} & \multirow{2}{*}{ SD } & \multirow{2}{*}{ IS } \\
\hline & 1 & 2 & 3 & Average & & \\
\hline $\mathrm{ABZ}$ & 0.3865 & 0.4176 & 0.4522 & 0.4188 & 0.03 & 1 \\
\hline $\mathrm{ABZ} / \beta \mathrm{CD}$ & 87.7026 & 91.1609 & 101.5427 & 93.4687 & 7.20 & 223 \\
\hline ABZ/ßCD-PVP & 122.5868 & 128.7522 & 124.6638 & 125.3343 & 3.14 & 299 \\
\hline $\mathrm{ABZ} / \mathrm{H} \beta \mathrm{CD}$ & 433.8756 & 457.9660 & 437.3408 & 443.0608 & 13.02 & 1058 \\
\hline ABZ/HPßCD-PVP & 566.8074 & 596.6097 & 620.2490 & 591.2220 & 22.22 & 1412 \\
\hline$\overline{F B Z}$ & 0.0811 & 0.1096 & 0.1255 & 0.1054 & 0.02 & 1 \\
\hline $\mathrm{FBZ} / \beta \mathrm{CD}$ & 41.1571 & 47.7081 & 47.8255 & 45.5636 & 3.82 & 432 \\
\hline FBZ/ $\beta C D-P V P$ & 32.5536 & 40.4370 & 41.3538 & 38.1148 & 4.48 & 362 \\
\hline $\mathrm{FBZ} / \mathrm{H} \beta \mathrm{CD}$ & 153.5421 & 165.5211 & 159.0208 & 159.3616 & 6.00 & 1512 \\
\hline FBZ/HPßCD-PVP & 140.0309 & 152.3906 & 141.5664 & 144.6626 & 6.74 & 1373 \\
\hline
\end{tabular}

*SD, standard deviation; IS, increase of solubility (expressed in number of times)

or quantitatively assessed by evaluating the concentration of the substance in the inclusion complexes. An indirect method to evaluate the quantity of substance within the CDs is to compare the amount of water in the CD and in the complexes. In the formation of the complexes, the water molecules inside the cavity of the $\mathrm{CD}$ are replaced by the guest molecule. Through thermogravimetric analysis of the CDs and complexes between ambient temperature and a temperature below $100{ }^{\circ} \mathrm{C}$, one can evaluate the release of water from the inside of the cavity of the CD and its replacement by the guest molecule (Moriwaki et al., 2008; Hădărugă, Hădărugă, Isengard, 2012). In this case, the binary and ternary complexes showed a reduction of the water bonded to the inside of the cavity of the CDs, suggesting the replacement of water molecules and the interaction of the guest molecule with the CDs (Table III).

The diffractogram revealed intense reflections at $7,11.2^{\circ}, 13.8^{\circ}, 17.9^{\circ}$, and $22^{\circ}(2 \theta)$ for ABZ; and at $6.6^{\circ}, 11^{\circ}, 13^{\circ}, 25.9^{\circ}$, and $26.3^{\circ}(2 \theta)$ for FBZ, which are

TABLE III - Thermal parameters obtained from the DSC and TG/DTG curves of the drugs (ABZ and FBZ) and binary and ternary complexes

\begin{tabular}{|c|c|c|c|c|c|}
\hline & DSC & & $\mathrm{TG}_{<100^{\circ} \mathrm{C}}$ & TG & \\
\hline & $\mathrm{T}_{\text {peak }}\left({ }^{\circ} \mathrm{C}\right)$ & $\Delta \mathrm{H}\left(\mathrm{J} \mathrm{g}^{-1}\right)$ & $\Delta \mathrm{m}(\%)$ & $\mathrm{T}_{\text {initial }}\left({ }^{\circ} \mathrm{C}\right)$ & $\Delta \mathrm{m}(\%)$ \\
\hline$\beta C D$ & & & 13.726 & $29 / 166$ & $14 / 84$ \\
\hline $\mathrm{HP} \beta \mathrm{CD}$ & & & 5.596 & $28 / 144$ & $6 / 94$ \\
\hline$\overline{\mathrm{ABZ}}$ & $199 / 213$ & $-78 /-3$ & 0.044 & $200 / 225 / 322 / 379 / 464$ & $4 / 8 / 15 / 32 / 19^{*}$ \\
\hline $\mathrm{ABZ} / \beta \mathrm{CD}$ & $186-200$ & -42 & 10.110 & $29 / 150 / 257$ & $10 / 3 / 72$ \\
\hline ABZ/ßCD-PVP & $187-200$ & -39 & 9.827 & $30 / 155 / 259 / 393$ & $10 / 3 / 58 / 16$ \\
\hline $\mathrm{ABZ} / \mathrm{HP} \beta \mathrm{CD}$ & $187-204$ & -28 & 4.508 & $32 / 145 / 255$ & $5 / 2 / 85$ \\
\hline ABZ/HPßCD-PVP & $187-203$ & -25 & 5.182 & $31 / 131 / 239 / 405$ & $6 / 2 / 70 / 16$ \\
\hline FBZ & $214 / 226$ & $-105 /-11$ & 0.061 & $204 / 230 / 274 / 390 / 538$ & $4 / 7 / 12 / 44 / 10^{*}$ \\
\hline $\mathrm{FBZ} / \beta \mathrm{CD}$ & $206-219$ & -65 & 8.900 & $26 / 165 / 273$ & $11 / 3 / 70$ \\
\hline FBZ/ $/ \beta C D-P V P$ & $204-221$ & -57 & 9.590 & $28 / 132 / 261$ & $10 / 3 / 72$ \\
\hline FBZ/HP $\beta C D$ & $206-226$ & -34 & 5.124 & $29 / 137 / 260$ & $5 / 2 / 83$ \\
\hline FBZ/HP $\beta C D-P V P$ & $204-229$ & -38 & 5.260 & $30 / 125 / 254$ & $5 / 2 / 87$ \\
\hline
\end{tabular}

*waste 
characteristics of the crystallinity of the compounds. $\beta C D$ revealed intense reflections at $6.1^{\circ}, 8.9^{\circ}, 10.5^{\circ}$, $12.4^{\circ}, 12.6^{\circ}$, and $15.3^{\circ}(2 \theta)$, which are characteristic of the crystallinity of the substance. HP $\beta C D$ and PVP had amorphous behavior. The physical mixtures of the drugs (ABZ or FBZ) with both CDs ( $\beta C D$ or HP $\beta C D)$ had reflections that were characteristic of each one of the isolated substances; the presence of PVP did not favor the amorphization of the mixtures. The binary and ternary complexes had a behavior similar to the physical mixtures, but with less intense reflections.

According to Pradines et al. (2014) the increase in the solubility of drugs in the presence of CDs cannot be attributed only to the formation of inclusion complexes, but also to the formation of self-organizing CD nanoclusters, which increase the solubility of the hydrophobic molecule through a micellar-type mechanism. The stability constant $\left(k_{c}\right)$ describes the result of all the effects of the CDs on the solubility of the drug. Not only inclusion complexes and noninclusion complexes are formed in the aqueous CD solution, but also bonds with the hydrogen molecules of neighboring CDs, forming self-organizing CD aggregates with an approximate diameter of $100 \mathrm{~nm}$ (Messner et al., 2010).

Table IV shows the mean hydrodynamic radius $\left(R_{H}\right)$, polydispersity index $(\mathrm{PI})$, and zeta potential $(\mathrm{Z})$ values of the drugs (ABZ and FBZ), the CDs ( $\beta C D$ and $\mathrm{HP}(\mathrm{CD})$, and the binary and ternary complexes. Although the modified CDs have functional groups on their surface that prevent self-clustering, self-organizing $\mathrm{CD}$ aggregates were observed in the binary and ternary systems for both CDs (Table IV). In the systems obtained with $\beta C D$, nanoclusters with a mean hydrodynamic radius of $188.6 \pm 11.7 \mathrm{~nm}$ were identified; in the systems obtained with $\mathrm{HP} \beta C D, C D$ aggregates $(180.9 \pm 4.5 \mathrm{~nm})$ and $C D$ monomers $(1.4 \pm 0.3 \mathrm{~nm})$ were observed. The results are in agreement with the literature (Coleman et al., 1992; González-Gaitano et al., 2002; Wu, Shen, He, 2006; Glisoni et al., 2012).

Negative zeta potential $(Z)$ values were obtained, indicating the stability of the complexes formed. The presence of the water-soluble polymer seems to favor steric repulsion, since the zeta potential $(Z)$ values in ternary complexes were, in absolute value, larger than those of the corresponding binary complexes. All samples showed high polydispersity ( $\mathrm{PI}>0.08$ ).

Nuclear magnetic resonance spectroscopy (NMR) is one of the most commonly used techniques for analysis of the stability, stoichiometry, and geometry of inclusion complexes, because it allows study of the interactions between the guest molecule and the CD directly. ${ }^{1} \mathrm{H}$ NMR studies can be used to monitor changes in the chemical shifts of protons as the composition of the complexes is

TABLE IV - Mean values of hydrodynamic radius $\left(R_{H}, \mathrm{~nm}\right)$, polydispersity index (IP) and zeta potential $(\mathrm{Z}, \mathrm{mV})$ of drugs, CDs and binary and ternary complexes $(n=6)$

\begin{tabular}{|c|c|c|c|c|}
\hline & $D_{H}(\mathrm{~nm})$ & I (\%) & IP & $\mathrm{Z}(\mathrm{mV})$ \\
\hline$\beta C D$ & $188.6 \pm 11.7$ & 100 & 0.627 & \\
\hline $\mathrm{HP} \beta C D$ & $\begin{array}{c}180.9 \pm 4.5 \\
1.4 \pm 0.3\end{array}$ & $\begin{array}{l}88.8 \\
11.2\end{array}$ & 0.457 & \\
\hline$\overline{\mathrm{ABZ}}$ & $564.7 \pm 42.61$ & 100 & 1.00 & $-32.5 \pm 5.14$ \\
\hline $\mathrm{ABZ} / \beta \mathrm{CD}$ & $\begin{array}{l}715.7 \pm 167.5 \\
167.8 \pm 29.82\end{array}$ & $\begin{array}{l}82.4 \\
17.6\end{array}$ & 0.568 & $-27.1 \pm 4.80$ \\
\hline $\mathrm{ABZ} / \beta C D-P V P$ & $\begin{array}{l}555.0 \pm 167.4 \\
137.2 \pm 27.94\end{array}$ & $\begin{array}{l}85.9 \\
11.9\end{array}$ & 0.555 & $-33.8 \pm 5.29$ \\
\hline $\mathrm{ABZ} / \mathrm{HP} \beta \mathrm{CD}$ & $871.4 \pm 195.8$ & 100 & 0.574 & $-23.7 \pm 3.74$ \\
\hline ABZ/HP $\beta C D-P V P$ & $969.4 \pm 98.11$ & 100 & 0.177 & $-24.1 \pm 4.55$ \\
\hline FBZ & $\begin{array}{l}838.7 \pm 232.1 \\
237.2 \pm 56.44\end{array}$ & $\begin{array}{l}79.8 \\
20.2\end{array}$ & 0.586 & $-34.6 \pm 4.41$ \\
\hline $\mathrm{FBZ} / \beta \mathrm{CD}$ & $680.4 \pm 119.5$ & 100 & 0.496 & $-27.8 \pm 4.70$ \\
\hline FBZ/ßCD-PVP & $\begin{array}{l}510.8 \pm 122.5 \\
140.6 \pm 23.88\end{array}$ & $\begin{array}{l}84.5 \\
15.5\end{array}$ & 0.549 & $-29.7 \pm 4.87$ \\
\hline FBZ/HP $\beta C D$ & $491.4 \pm 191.9$ & 100 & 0.557 & $-31.2 \pm 4.42$ \\
\hline FBZ/HP $\beta C D-P V P$ & $\begin{array}{l}757.6 \pm 239.3 \\
218.0 \pm 53.83\end{array}$ & $\begin{array}{l}77.3 \\
20.5\end{array}$ & 0.568 & $-33.5 \pm 4.91$ \\
\hline
\end{tabular}


varied, and, as such, they provide information about the stoichiometry of the complexes and the dynamics of their formation. At the same time, when the drug is incorporated into the cavity of the $\mathrm{CD}$, the hydrogen atoms located inside them (H-3 and H-5) undergo a significant chemical shift to higher value ranges, while the hydrogen atoms located on the outer surface of the CD $(\mathrm{H}-1, \mathrm{H}-2, \mathrm{H}-4$, and $\mathrm{H}-6)$ are either not affected or undergo negligible shifts (Fernandes et al., 2003; Ikeda et al., 2004; Ferreira et al., 2015).

Figure 2 shows the ${ }^{1} \mathrm{H}$ NMR spectra of the benzimidazoles, ABZ (A) or FBZ (B), recorded at 300 $\mathrm{MHz}$ in DMSO- $d_{6}$ with the signal assignments of the hydrogens. Figure 3 corresponds to the ABZ spectra in $\beta C D$ binary $(A)$ and ternary (B) systems. The spectrum recorded for $\mathrm{ABZ}$ in the presence of $\beta C D$ (A) reveals the presence of signals corresponding to the drug and the cyclodextrin. The absence of protection, and the broadening of the signals in the range between 6 and 4 ppm, corresponding to $\mathrm{OH}$ groups and $\mathrm{CH}_{2}$ groups of the pyran rings present in the $\beta C D$ structure, suggest there are intermolecular interactions between the drug and $\beta C D$, but not effective complexation (Moriwaki et al., 2008; De Jaeghere et al., 2013). The addition of PVP (B) caused changes in the profile of the hydroxyl groups at $5.70 \mathrm{ppm}$ (broad singlet), suggesting a better interaction between $A B Z$ and $\beta C D$ in the presence of PVP.

The ${ }^{1} \mathrm{H}$ NMR spectra of ABZ in the presence of HP $\beta C D$ indicate the low solubility of the drug and the attempt to form inclusion complexes as shown in Figure 4 (A). The addition of the water-soluble polymer did not significantly alter the solubility of the system; no change in ${ }^{1} \mathrm{H}$ NMR parameters was observed in Figure 4 (B).

Figure 5 shows the ${ }^{1} \mathrm{H}$ NMR spectra of FBZ in the binary systems with $\beta C D(A)$ and $\operatorname{HP} \beta C D(B)$. The ${ }^{1} \mathrm{H}$ NMR spectra of FBZ in the presence of both CDs revealed the presence of signals corresponding to the drug and the CDs, suggesting an interaction between the molecules. In the ${ }^{1} \mathrm{H}$ NMR spectrum of FBZ in the presence of HP $\beta C D$ (B), enlargement and distortion of the signals in the region between 6 and to $4 \mathrm{ppm}$ is visible, corresponding to the $\mathrm{OH}$ groups and $\mathrm{CH}_{2}$ groups of the pyran rings present in the HP $\beta C D$ structure, indicating effective complexing between FBZ and HP $\beta C D$. The spectra recorded after the addition of PVP to the binary systems FBZ/CD ( $\beta C D$ or HP $\beta C D$ ) did not reveal any alterations in the NMR spectrum.

The great importance of CDs in the development of medication containing low-solubility drugs lies in their ability to act as the carrier of hydrophilic drugs, thereby increasing the solubility and/or dissolution rate, and, consequently, the bioavailability of these drugs (Challa et al., 2005). The dissolution trials of the drugs and their complexes enabled the identification of differences in the dissolution rate of the binary and ternary complexes in
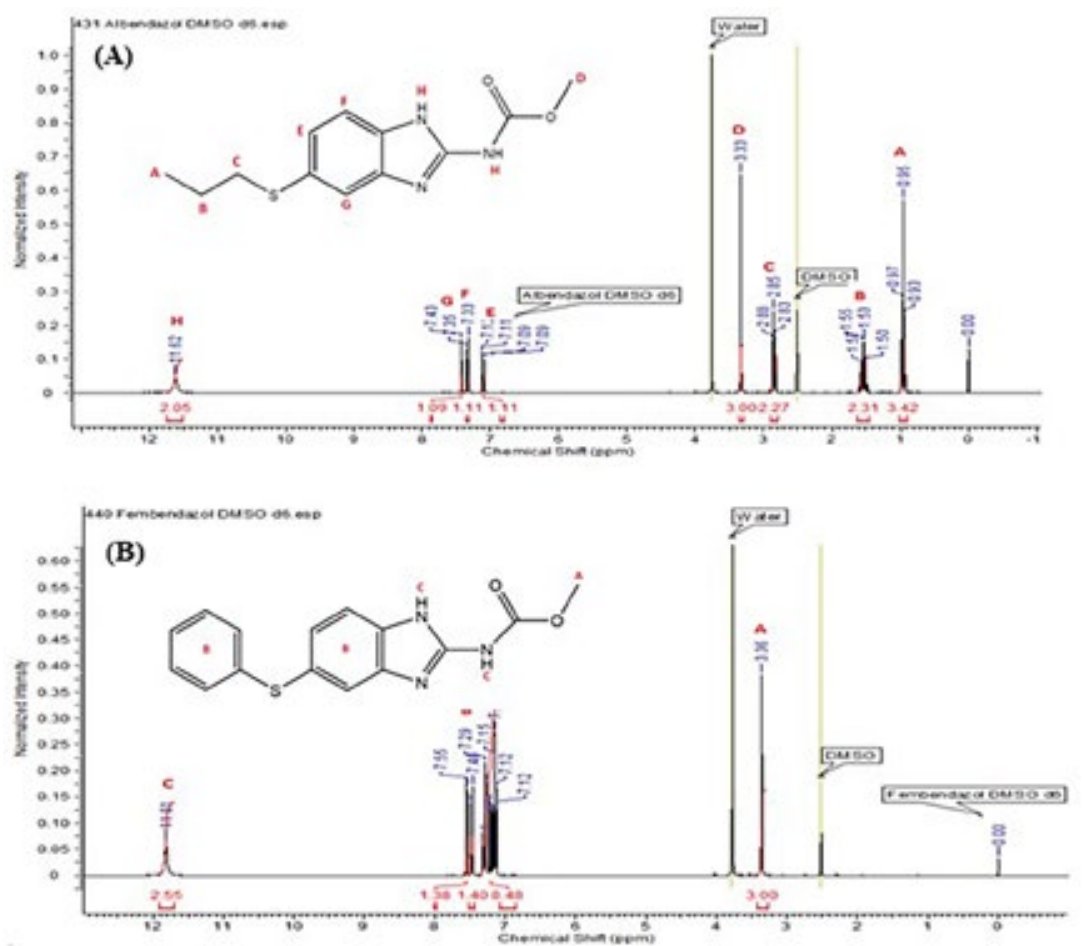

FIGURE 2 - ${ }^{1} \mathrm{H}-\mathrm{NMR}$ spectra of ABZ (A) and FBZ (B) recorded in $300 \mathrm{MHz}$ DMSO-d6. 

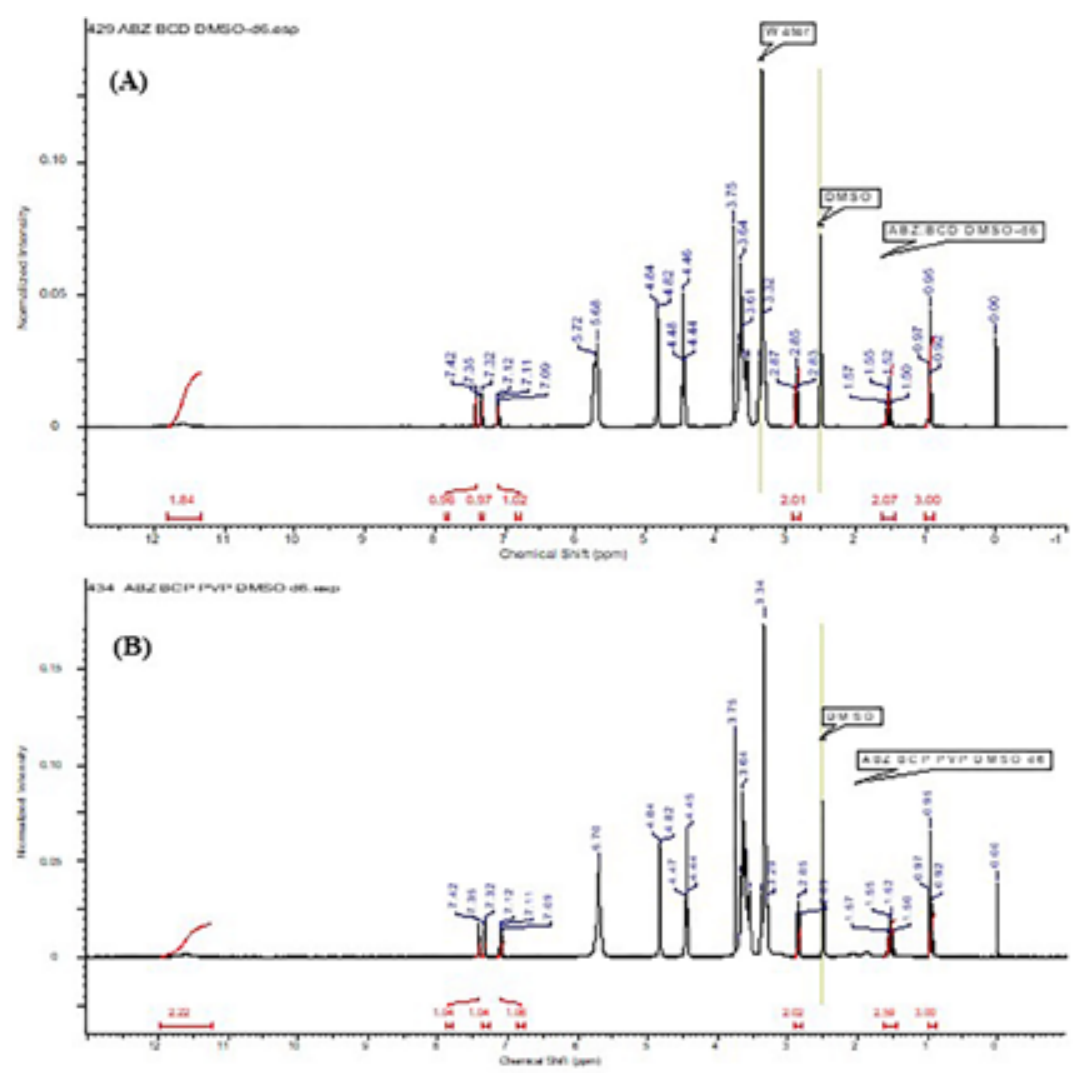

FIGURE 3 - 'H-NMR spectra of ABZ in the presence of $\beta C D$ (A) and the water-soluble polymer (PVP) (B) recorded in $300 \mathrm{MHz}$ DMSO-d6.
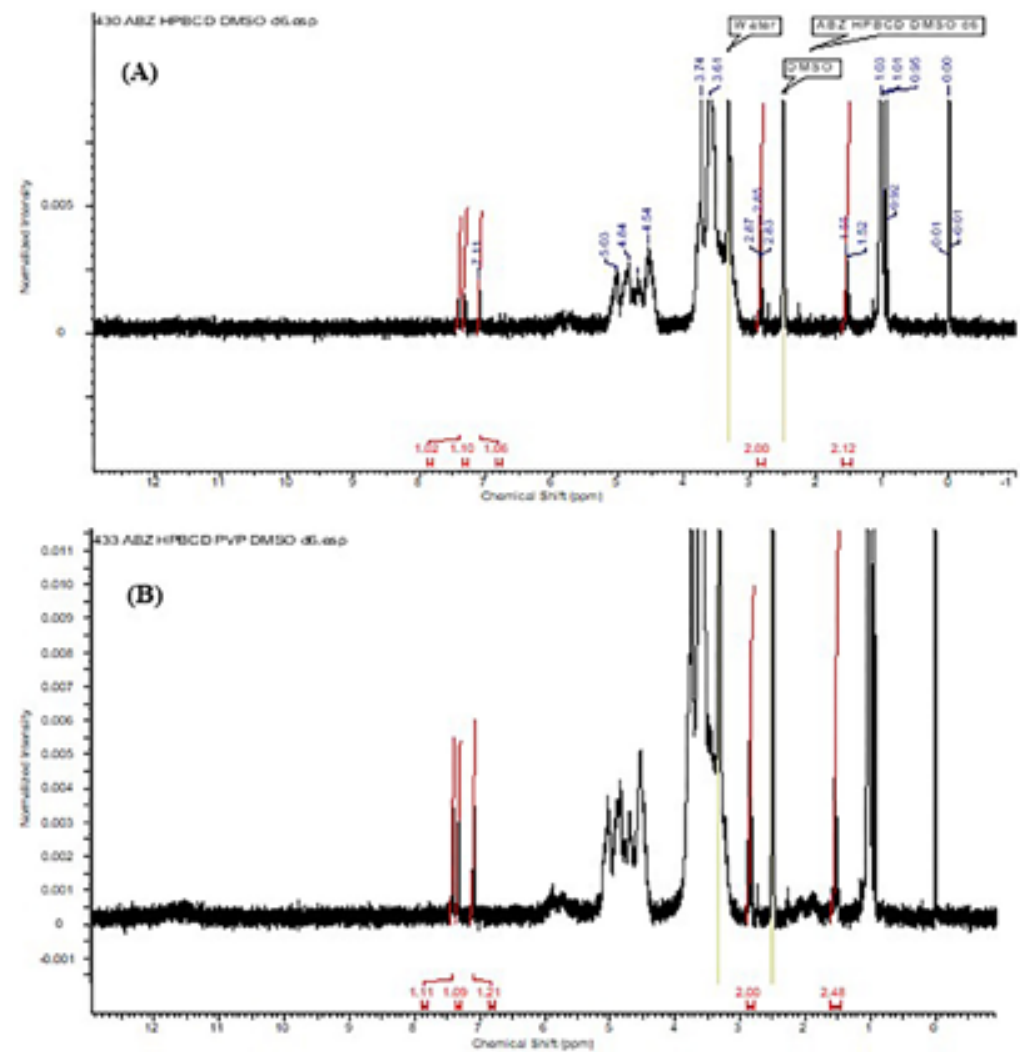

FIGURE $4-{ }^{1} \mathrm{H}-\mathrm{NMR}$ spectrum of ABZ in the presence of $\operatorname{HP} \beta C D(\mathrm{~A})$ and the water-soluble polymer (PVP) (B) recorded in $300 \mathrm{MHz}$ DMSO-d6. 

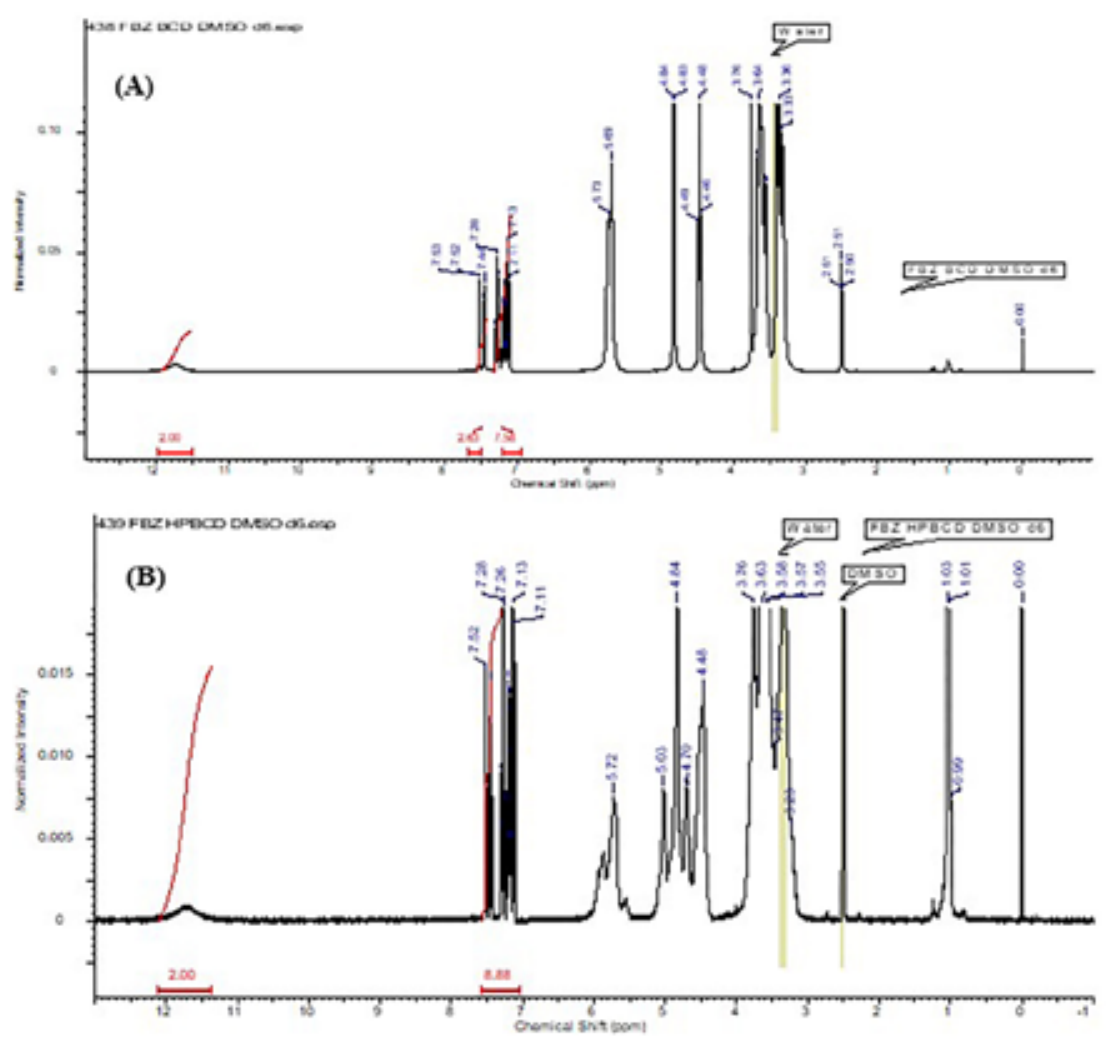

FIGURE 5 - ${ }^{1} \mathrm{H}-\mathrm{NMR}$ spectra of FBZ in the presence of $\beta \mathrm{CD}(\mathrm{A})$ and $\mathrm{HP} \beta \mathrm{CD}(\mathrm{B})$ recorded in $300 \mathrm{MHz}$ DMSO-d6.

relation to the pure drugs. The dissolution rates of the pure drugs and of the binary and ternary complexes obtained with $\beta C D$ were lower than that observed for HP $\beta C D$. In turn, the ternary complexes obtained with HP $\beta C D$ had higher dissolution rates than the binary complexes (Figure 6). According to Kumar et al. (2011b) the increase in solubility and dissolution rate of FBZ in binary and ternary complexes obtained with $\beta$-cyclodextrin and

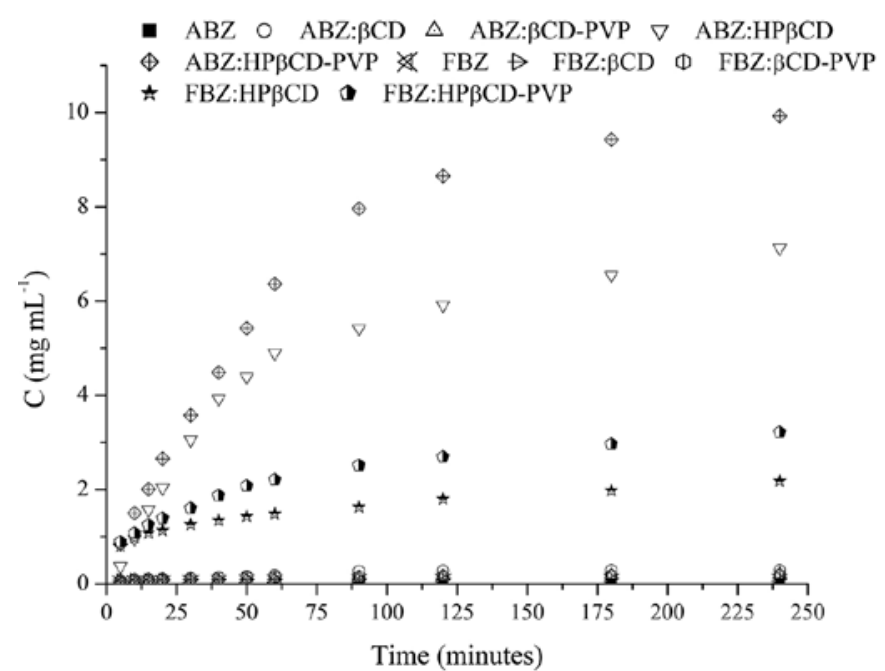

FIGURE 6 - Amount dissolved versus time obtained for the drugs (ABZ and FBZ) and their binary and ternary complexes.
PVP-k-30 can be attributed to the increase in the drug's wetting properties.

\section{CONCLUSION}

Among the CDs compared in this study to increase the solubility of the benzimidazole-2-carbamates albendazole and fenbendazole, hydroxypropyl- $\beta$ cyclodextrin showed the most potential. A synergistic effect between the water-soluble polymers PVP-k30 and $\mathrm{HP} \beta C D$ enabled a significant increase in the solubility and dissolution rate of the drugs.

The analysis of the changes in displacement and the profile of the bands matching the cyclodextrins in the ${ }^{1} \mathrm{H}$ NMR spectra revealed a molecular interaction and pointed to an effective complexation in the drug/CD systems.

The increase in the solubility of the drugs, either by the formation of inclusion complexes or by the formation of self-organizing CD aggregates, constitutes a promising strategy for the pharmaceutical industry to increase the solubility of these drugs. However, in addition to low solubility, ABZ and FBZ have other problems, such as poor stability and intestinal permeability. Therefore, the biological evaluation of these drugs and their complexes will be pursued in our future studies. 


\section{ACKNOWLEDGMENTS}

We recognize that this research would not have been possible without the financial support of Fundação de Amparo a Pesquisa do Estado de São Paulo (FAPESP) [2013/15704-3] and so we would like to express our gratitude to this agency. We would also like to thank Labonathus Biotenologia International Ltda. (Brazil) to supply the $\beta C D$ used in this study.

\section{REFERENCES}

Alamdarnejad G, Sharif A, Taranejoo S, Janmaleki M, Reza Kalaee M, Dadgar M, et al. Synthesis and characterization of thiolated carboxymethyl chitosan-graft-cyclodextrin nanoparticles as a drug delivery vehicle for albendazole. J Mater Sci-Mater Med. 2013;24(8):1939-49.

Aronson H. Correction factor for dissolution profile calculations. J Pharm Sci. 1993;82(11):1190.

Camacho J, Barazarte A, Gamboa N, Rodrigues J, Rojas $\mathrm{R}$, Vaisberg A, et al. Synthesis and biological evaluation of benzimidazole-5-carbohydrazide derivatives as antimalarial, cytotoxic and antitubercular agents. Bioorg Med Chem. 2011;19(6):2023-9.

Challa R, Ahuja A, Ali J, Khar RK. Cyclodextrins in drug delivery: an updated review. AAPS PharmSciTech. 2005;6(2):E329-E57.

Coleman AW, Nicolis I, Keller N, Dalbiez JP. Aggregation of cyclodextrins: an explanation of the abnormal solubility of $\beta$ cyclodextrin. J Inclus Phenom Mol. 1992;13(2):139-43.

Daniel-Mwambete K, Torrado S, Cuesta-Bandera C, PonceGordo F, Torrado JJ. The effect of solubilization on the oral bioavailability of three benzimidazole carbamate drugs. Int $\mathbf{J}$ Pharm. 2004;272(1/2):29-36.

De Jaeghere W, De Geest BG, Van Bocxlaer J, Remon JP, Vervaet C, Fonseca AA. Formulation of poorly water-soluble drugs via coacervation - a pilot study using febantel. Eur J Pharm Biopharm. 2013;85(3)930-5.

Duan Q, Liu Y, Rockwell S. Fenbendazole as a potential anticancer drug. Anticancer Res. 2013;33(2):355-62.
Evrard B, Chiap P, DeTullio P, Ghalmi F, Piel G, Van Hees $\mathrm{T}$, et al. Oral bioavailability in sheep of albendazole from a suspension and from a solution containing hydroxypropyl- $\beta$ cyclodextrin. J Control Release. 2002;85(1-3):45-50.

Fernandes CM, Carvalho RA, Costa S, Veiga FJB. Multimodal molecular encapsulation of nicardipine hydrochloride by $\beta$-cyclodextrin, hydroxypropyl- $\beta$-cyclodextrin and triacetyl$\beta$-cyclodextrin in solution. Structural studies by $1 \mathrm{H}$ NMR and ROESY experiments. Eur J Pharm Sci. 2003;18(5):285-96.

Ferreira MJG, García A, Leonardi D, Salomon CJ, Lamas MC, Nunes TG. 13C and 15N solid-state NMR studies on albendazole and cyclodextrin albendazole complexes. Carbohyd Polym. 2015;123:130-5.

Glisoni RJ, Chiappetta DA, Moglioni AG, Sosnik A. Novel 1-indanone thiosemicarbazone antiviral candidates: aqueous solubilization and physical stabilization by means of cyclodextrins. Pharm Res. 2012;29(3):739-55.

González-Gaitano G, Rodríguez P, Isasi JR, Fuentes M, Tardajos G, Sánchez M. The aggregation of cyclodextrins as studied by photon correlation spectroscopy. J Inclusion Phenom Macrocyclic Chem. 2002;44(1/4):101-5.

Heydari S, Kakhki RM. Thermodynamic study of complex formation of $\beta$-cyclodextrin with ibuprofen by conductometric method and determination of ibuprofen in pharmaceutical drugs. Arab J Chem. 2013;10(Suppl 1):S1223-S6.

Higuchi T, Connors KA. Advances in analytical chemistry instrumentation. New York: Wiley-Interscience; 1965. v.4.

Hădărugă NG, Hădărugă DI, Isengard HD. Water content of natural cyclodextrins and their essential oil complexes: a comparative study between Karl Fischer titration and thermal methods. Food Chem. 2012;132(4):1741-48.

ICH. International Conference on Harmonization of Technical Requirements for Registration of Pharmaceutical for Humam use. Harmonised Tripartite Guidelines. Validation of analytical Procedures: Text and Methodology Q2(R1). 2005.

Ikeda Y, Hirayama F, Arima H, Uekama K, Yoshitake Y, Harano K. NMR spectroscopic characterization of metoprolol/ cyclodextrin complexes in aqueous solution: cavity size dependency. J Pharm Sci. 2004;93(7):1659-71. 
Kumar V, Shankaraiah M, Venkatesh J, Rangaraju D, Nagesh C. Characterization of ternary system of poorly soluble drug in various hidrophilic carriers. Int Res J Pharm. 2011a;2(9):143-5.

Kumar V, Venkatesh J, Shankaraiah M, Kant A, Nagesh C. Improving the solubility of antihelmintic drug by solid dispersions and inlcusion complexes. Int Res J Phar. 2011b;2(8):100-4.

Kurkov SV, Loftsson T. Cyclodextrins. Int J Pharm. 2013;453(1):167-80.

Loftsson T, Másson M, Sigurjónsdóttir J. Methods to enhancemthe complexation efficiency of cyclodextrins. STP Pharma Sci. 1999;9(3):237-42.

Messner M, Kurkov SV, Jansook P, Loftsson T. Self-assembled cyclodextrin aggregates and nanoparticles. Int J Pharm. 2010;387(1-2):199-208.

Miranda JC, Martins TEA, Veiga F, Ferraz HG. Cyclodextrins and ternary complexes: technology to improve solubility of poorly soluble drugs. Braz J Pharm Sci. 2011;47(4):665-81.

Moriwaki C, Costa G, Moraes F, Zanin G, Pineda E, Matioli G. Enhancement of solubility of albendazole complexation with $\beta$-cyclodextrin. Braz J Chem Eng. 2008;25(2):255-67.

Palomares-Alonso F, González CR, Bernad-Bernad MJ, Montiel MDC, Hernández GP, González-Hernández I, et al. Two novel ternary albendazole-cyclodextrin-polymer systems: dissolution, bioavailability and efficacy against Taenia crassiceps cysts. Acta Trop. 2010;113(1):56-60.
Pharmacopeia of the United States of America: USP39, National Formulary: NF34. Rockville: United States Pharmacopeial Convention; 2016.

Pitha J, Szente L, Greenberg J. Poly-L-methionine sulfoxide: a biologically inert analogue of dimethyl sulfoxide with solubilizing potency. J Pharm Sci. 1983;72(6):665-8.

Pourgholami M, Wangoo K, Morris D. Albendazole-cyclodextrin complex: enhanced cytotoxicity in ovarian cancer cells. Anticancer Res. 2008;28:2775-2779.

Pradines B, Gallard JF, Iorga BI, Gueutin C, Loiseau PM, Ponchel $\mathrm{G}$, et al. Investigation of the complexation of albendazole with cyclodextrins for the design of new antiparasitic formulations. Carbohydr Res. 2014;398:50-55.

Rodrigues LNC, Reis, AKCA, Katiki, LM. Development and validation of the rp-hplc method for determination of benzimidazole carbamates in the presence of cyclodextrins. Int Res J Pharm. 2016;7(12):30-4.

Stella VJ, Rajewski RA. Cyclodextrins: their future in drug formulation and delivery. Pharm Res. 1997;14(5):556-67.

Wu A, Shen X, He Y. Investigation on $\gamma$-cyclodextrin nanotube induced by $\mathrm{N}, \mathrm{N}$ '-diphenylbenzidine molecule. J Colloid Interface Sci. 2006;297(2):525-33.

Received for publication on $30^{\text {th }}$ November 2017 Accepted for publication on $16^{\text {th }}$ May 2018 